\title{
Occurrence of Canine Skin Disorder and its Haematobiochemical Alterations
}

\author{
Geetanjali Thapa* and Samar Sarkar
}

Department of Veterinary Medicine, Ethics and Jurisprudence, Faculty of Veterinary and Animal Sciences, WBUAFS, Kolkata-37, India

*Corresponding author

\begin{tabular}{|l|}
\hline Ke y w o r d s \\
Dermatological disorder, \\
$\begin{array}{l}\text { Dog, Occurrence, } \\
\text { Haematological and } \\
\text { biochemical parameters }\end{array}$ \\
\hline Article Info \\
\hline $\begin{array}{l}\text { Accepted: } \\
\text { 04 November } 2018 \\
\text { Available Online: } \\
\text { 10 December } 2018\end{array}$ \\
\hline
\end{tabular}

\section{Introduction}

Skin disorder is one of the most commonly encountered problem in pet animals. Dogs are susceptible to various skin problems be it parasitic, fungal, bacterial skin disease or allergies of various origin. These conditions become worse in hot and humid climate therefore becoming difficult to resolve. This not only deteriorates the cosmetic value of the animal but also poses a risk to its general health and utility. The present study was conducted with the objective of determining a
The present study was conducted to investigate a detailed occurrence of different dermatological problems in dogs in and around Kolkata and to determine the changes in the haematological and biochemical parameters of affected dogs. During a period of 6 months 156 dogs with primary complain of dermatological discomfort were studied, out of which the maximum number of animals were affected with skin disease caused by parasites i.e. $48(30.78 \%)$ followed by bacteria $45(28.85 \%)$. Dogs below 1 year of age were mostly susceptible (35.54\%) to various dermatological disorders and the least susceptible group were more than 4 years of age (16.03\%). Higher occurrence was observed in male dogs (61.02\%) in comparison to females. Results revealed that spitz were predisposed to various dermatological disorders $(27.56 \%)$ followed by Labrador $(19.87 \%)$. On examination of skin scrapping sarcoptic mange and demodectic mange were the commonly identified mites. The bacteria isolated from pyoderma of dogs were mostly Staphylococcus spp. followed by E.coli and Klebsiella sp. The haemoglobin, PCV and TEC values of affected animals had significantly decreased. The TLC significantly had significantly increased while serum globulin had decreased in affected animals. 
Belgachia and some private clinics in Kolkata with primary complain of skin problems. The dog's breed, gender, age was recorded to establish whether they were associated dermatological problems. The dog breed were assessed according to the official breed standard from the American Kennel club.

Thorough history was collected from the owners and the information thus obtained along with the observations made on the patient was recorded. Diagnosis was done by collecting skin scraping from dogs with complain of pruritus, alopecia, scaling or crusting, erythema, macular, pustular eruptions, erosive or ulcerative lesions for the identification of causative agent.

Skin scrapping of dogs suspected for mange infestation was collected and examined by sedimentation method and by direct smear method. For the direct smear method a few amount of skin scraping was placed on the centre of a clean microscopic slide. 2-3 drops of $10 \%$ potassium hydroxide was poured on to it. The scrapping was then triturated with a needle and the materials were dispersed in a thin layer by gently pressing the cover slip. The slide was gently warmed over a spirit lamp to soften the skin material and digest the keratin debris. The slide was allowed to cool and examination was done under low power microscope for the detection of parasites. For the sedimentation method skin scraping was transferred to a $15 \mathrm{ml}$ centrifuge tube and $5 \mathrm{ml}$ of $10 \%$ potassium hydroxide solution was added to it. Then the treated material was heated gently until the keratin debris dissolved. The material was then centrifuged at $3000 \mathrm{rpm}$ for $5 \mathrm{mins}$. The tube was allowed to cool for 5 mins. The supernatant fluid was discarded with a pipette. 1-2 drops of the sediment was transferred to a glass slide using a pipette. A cover slip was placed carefully and the slide was then examined under low power magnification.
For the fungal identification a pinch of infected materials collected was put on a clean dry slide along with one to two drops of $10 \%$ potassium hydroxide solution $(\mathrm{KOH})$ and then covered with a cover slip. The slide was then heated gently over a flame making sure that it does not boil and was examined after 15 mins under a microscope as suggested by Beneke (1966). It was first examined under low power microscope and then under high power microscope for the presence of any mycelia and spores. For the detailed study of fungus all the skin scrapping collected were examined culturally by using Sabourad's Dextrose agar fortified with cyclohexamide and chloramphenicol. Sabourad's dextrose agar slants were used initially. For the study of detailed morphology and colony characters, agar plates were used and incubated for a maximum period of 30 days. A portion of the colony was detached by the tip of a long sterile needle and then placed on a clean slide having a drop of Lacto phenol cotton blue. Then a thin coverslip was placed over it. This was now examined under a low power and then under high power objective of a microscope.

For the diagnosis of pyoderma, samples were collected in sterile cotton swabs Swabs collected from dogs affected with pyoderma were inoculated into Nutrient Broth and incubated at 37 for 24 hours and then a loopful of broth culture was streaked on nutrient agar plates. Based on morphology and Gram's staining properties, cultures were inoculated into specific/ selective media like Mannitol Salt Agar, Eosin Methylene Blue and MacConkey Agar.

\section{Haematological and Biochemical alterations}

For haemato-biochemical study the blood samples were collected from dogs with dermatological disorders and also from 6 
healthy animals for reference values. From each dog $7 \mathrm{ml}$ of blood was drawn from the recurrent tarsal vein or radial vein. Out of 7 $\mathrm{ml}, 5 \mathrm{ml}$ of blood was collected in sterilized test tubes without any anticoagulant for the separation of serum. Another $2 \mathrm{ml}$ of blood was collected in dried vials containing EDTA as anticoagulant $(1 \mathrm{mg} / \mathrm{ml})$ and mixed by rotating the tubes. This was then used for the determination of parameter like haemoglobin (Hb) by Sahil's method as described by Schalm et al., (1986) and is expressed in gm $\%$, packed cell volume (PCV) by micro haematocrit method and was expressed as percentage of the total volume as described by Schalm et al., 1986, total erythrocyte count (TEC) by haemocytometer as described by Schalm et al.,1986 and was expressed in per cubic millimeter $(106 / \mathrm{cmm})$, total leucocyte count (TLC) by haemocytometer as described by Schalm et al., 1986 and was expressed as thousands per cubic millimetre $(103 / \mathrm{cmm})$ of blood and differential leucocyte count (DLC) was estimated as described by Schalm et al., 1986 and expressed as percentage. Total serum protein and serum albumin levels were estimated by Biuret method of Reinhold (1953) in a VU-VIS Spectrophotometer at the wavelength of $550-600 \mathrm{~nm}$ and the values were expressed as $\mathrm{gm} / \mathrm{dl}$. Serum total globulin content was calculated as the difference between serum total protein and albumin levels.

All the data obtained in respect to the different parameters in this study have been statistically analysed as per Snedecor and Cochran, 1967.

\section{Results and Discussion}

\section{Occurrence study}

During the period of study (December 2016 May 2017), a total of 6,530 canine cases was registered at the Teaching Veterinary Clinical Complex, Belgachia, run round the clock including holidays, out of which 788 (12.06\%) had the complications of dermatological disorders. From the 788 dermatological cases a total of 156 cases were randomly selected on the basis of easy access to the cases and support of the owners for the present study for a detailed category wise occurrence.

The results of the present study are corroborated with the study of Shyma and Vijayakumar (2012) who reported $12 \%$ of dermatological problems in one year in dogs. Prevalence of skin disorders ranging from 15$25 \%$ in dogs had earlier been reported by Scott et al., 2001 and Hill et al., 2006.

On the contrary, the percentage of prevalence of dermatological affections as reported by Sharma et al., 2013 and Summers et al., 2014 were just $5.6 \%$ and $1.3 \%$. Higher prevalence of dermatological disorders may be due to season, climatic factors and management factors adopted in a particular area as stated by Sharma et al., (2008).

The occurrence of dermatological disorders according to the pathogens (Fig. 1) in this study showed that the maximum no. of dermatological problems were due to parasitic $(30.78 \%)$ followed by bacterial (28.85\%), fungal $(18.58 \%)$ and mixed skin infections $(12.82 \%)$. It was interesting to note that a substantial percentage $(8.97 \%)$ were of the non-infectious type which might be due to hypothyroidism, nutritional deficiencies or canine atopic dermatitis (Fig. 5-7).

It was observed that the occurrence of scabies was $38(24.36 \%)$ and that of canine demodicosis was $10(6.41 \%)$ out of the total of 156 skin affected dogs.

All the 156 cases were subjected to Wood's lamp screening, direct microscopic examination of hair pluckings, skin scrapping and cultural examination of fungal isolates, 29 
dogs were found to be positive for dermatomycosis.

45 out of the 156 cases were found positive in bacteriological culture were subjected to Gram's staining, 38 showed the presence of gram positive cocci while the remaining 7 revealed gram negative rods. Detailed cultural examination was carried out in 45 pyoderma samples from which 90 isolates were obtained and identified. 76 isolates were found to be positive for Staphylococcus species, 10 were positive for E. coli and 4 isolates were positive for Klebsiella.

A similar findings regarding the clinicoepidemiological studies in canine dermatitis was reported by Singh et al., 2012 with the highest prevalence of parasitic dermatitis (34.82\%) followed by bacterial (25\%), fungal (18.75\%), non-specific (14.28\%) and nutritional (7.14\%).

Lodh and Das (2014) also reported that dermatitis caused by ectoparasites were the maximum (28.01\%). Auijla (2000) and Sharma et al., 2008 reported $31.31 \%$ and $28.43 \%$ the prevalence of bacterial dermatitis respectively. Sumathi and Vasu (2009) observed $20.50 \%$ of fungal dermatitis in canines. The incidence of parasitic dermatitis was reported as $36.53 \%$ and $33.33 \%$ by Ayodhya et al., 2006 and Sharma et al., 2009respectively. All these findings are in close agreement to the findings of the present study.

The animals in this study were divided into 4 groups viz. group I (below 1 year), group II (in between 1-2 years), group III (in between 2-4 years) and group IV (more than 4years) (Fig. 2 ). The highest percentage was recorded in dogs of age group less than 1 year $(36.54 \%)$ followed by the age group 1-2 years (26.92\%), then $2-4$ years $(20.51 \%)$ and the least in the age group more than 4 years $(16.03 \%)$.
A very similar finding was noticed by Singh $e t$ al., 2012 who reported the highest occurrences of dermatitis in dogs in the age group of $0-1$ year $(42.17 \%)$ followed by the age group $1-2$ years $(22.44 \%)$ then the age group 2-3 years $(21.08 \%)$ and the lowest in the age group 3-4 years (14.28\%). Poor development of epithelium and lack of specific immunity acquired after first exposure could be the possible reason for increased skin infection in young dogs (Hay, 1992). Moreover high body temperature in young animals, high nutritive demand and overcrowding may also increase the susceptibility of young animals to skin infection (Scott, 1995). Further, biochemical properties of skin and skin secretions, especially low fatty acids in the sebum may also be responsible for the infection in young ones, as these fatty acids are highly fungistatic (Hay, 1992).

The findings of the present study is also in close agreement to Khurana et al., 2016 who reported the maximum occurrence of dermatological problem in canines at the age group of below 1 year (40.90\%) followed by the age group of 1-2 years, then between 2-4 years and the least in the age group of above 4 years of age. However, Kumar et al., 2006 also reported that the maximum no. of cases of all skin disorders was observed in the age group of 1-3 years. Among the skin disordersaffected dogs, maximum numbers were of males $(61.02 \%)$ whereas females constituted only $38.98 \%$ (Fig. 3). The findings of the present study is similar to that of Kumar et al., 2006 who reported that males dogs were found to suffer from various skin diseases more as compared to female dogs. Khurana et al., 2016 also reported a close finding i.e. $63.22 \%$ of male dogs and $36.78 \%$ of female dogs were affected with various skin disorders. The difference between male and female as far as the occurrence according to the sex did not draw any conclusion. This warrants further study. 
Int.J.Curr.Microbiol.App.Sci (2018) 7(12): 184-195

Fig.1

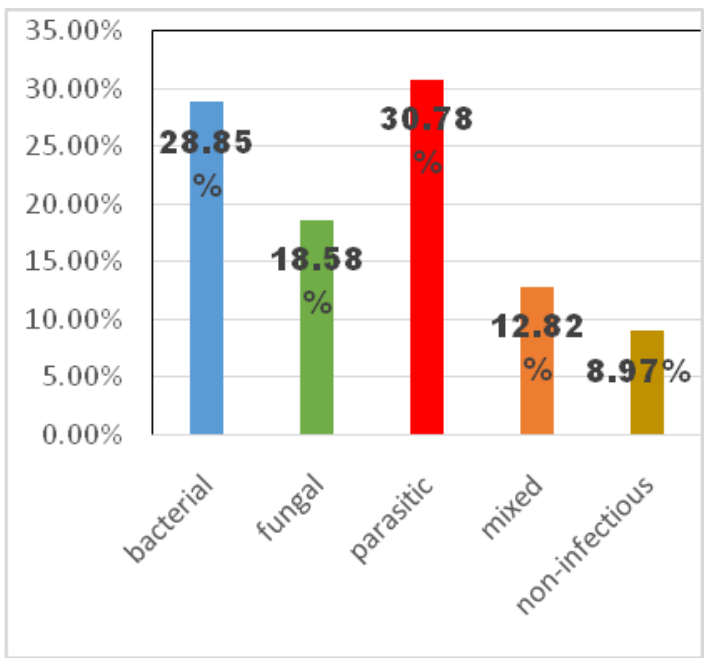

Fig.2

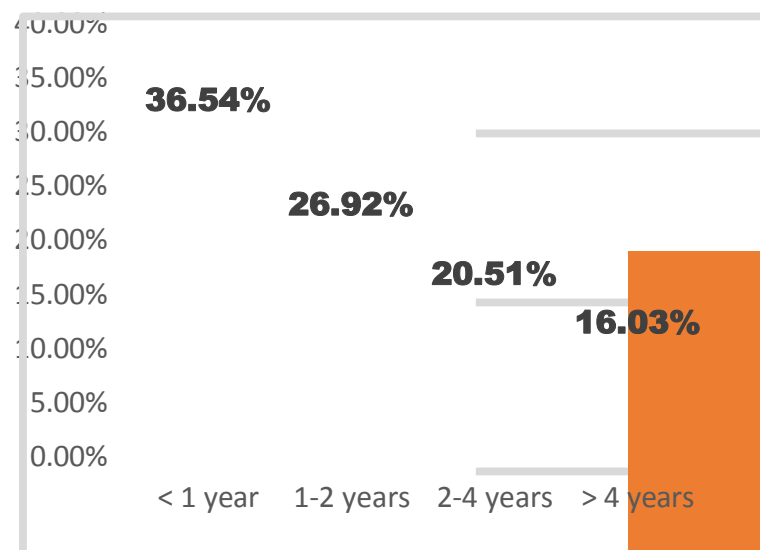

Fig.3

$39.10 \%$

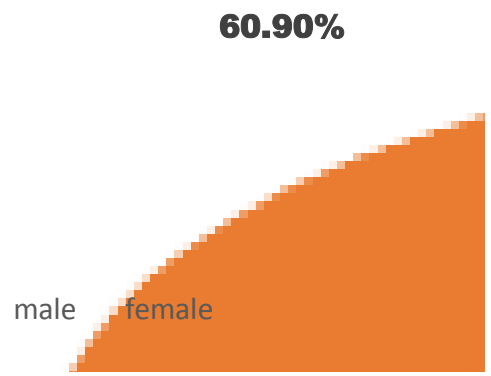


Fig.4

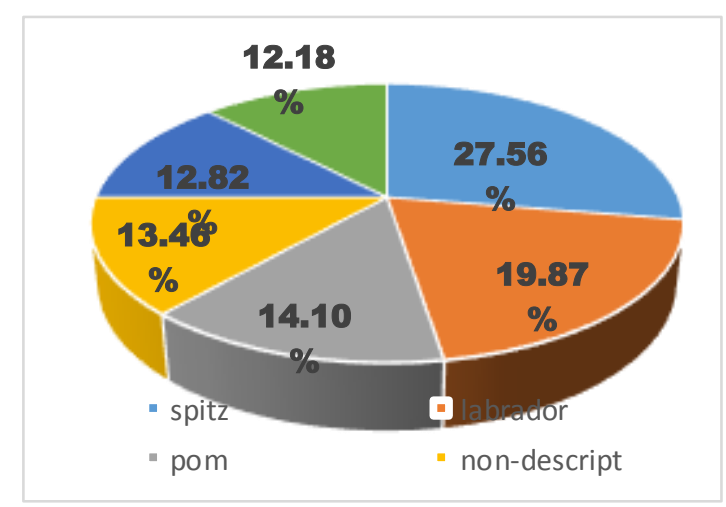

Fig.5 Photograph showing symptomatology of skin disorders (a) Papules (b) Pustules (c) hot spots (d) patchy alopaecia with dry scales (e) typical ringworm lesions

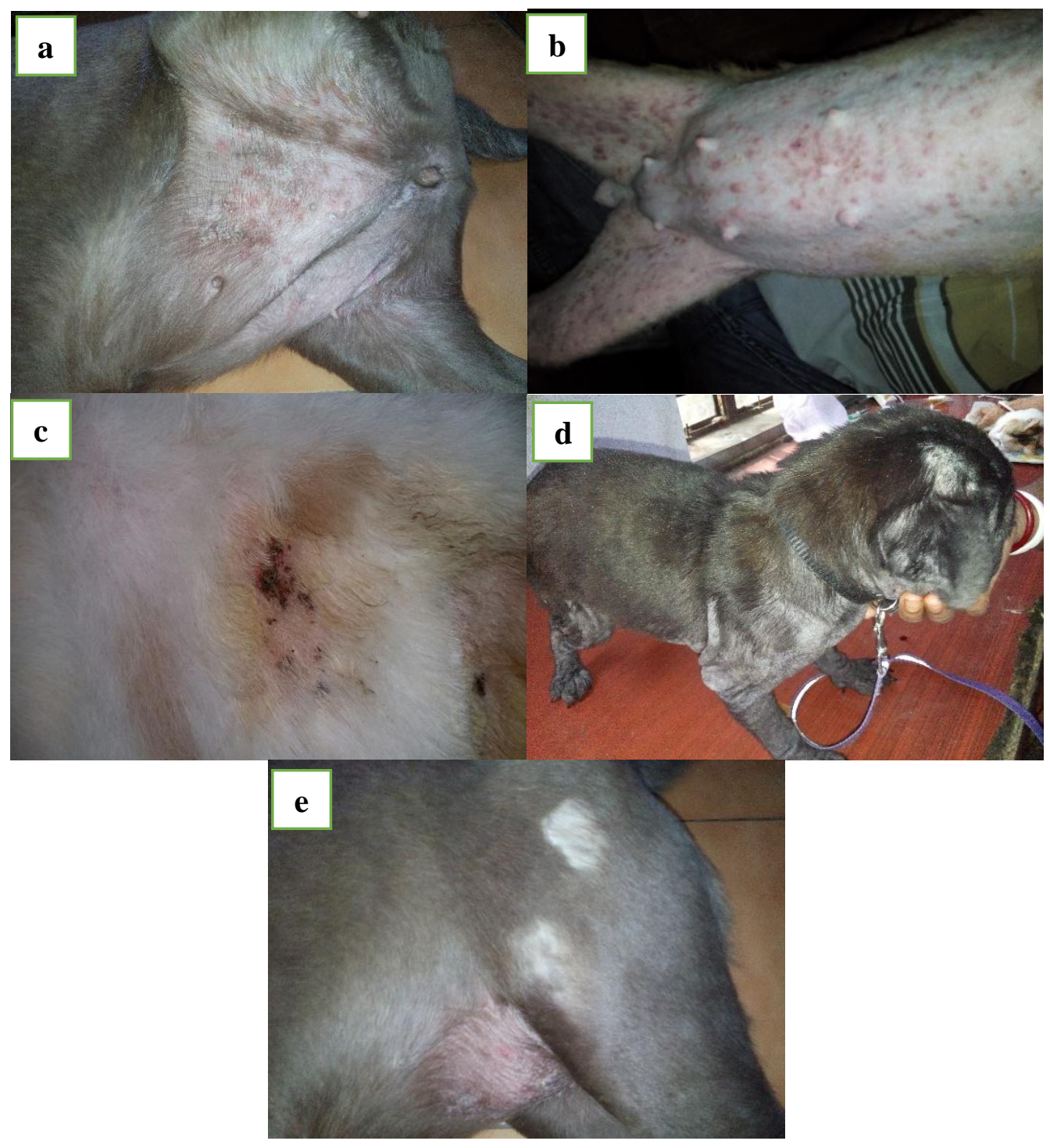


Fig.6 Photograph showing (a) Sarcoptes scabiei on microscopic examination (b) Demodexcanis on microscopic examination. (c) fluorescence of hair produced by Microsporum canis on Wood's lamp examination (d) E.coli in EMB agar (e) Klebsiella in MacConkey agar (f)

Mannitol fermenting colonies of Staphylococcus sp.

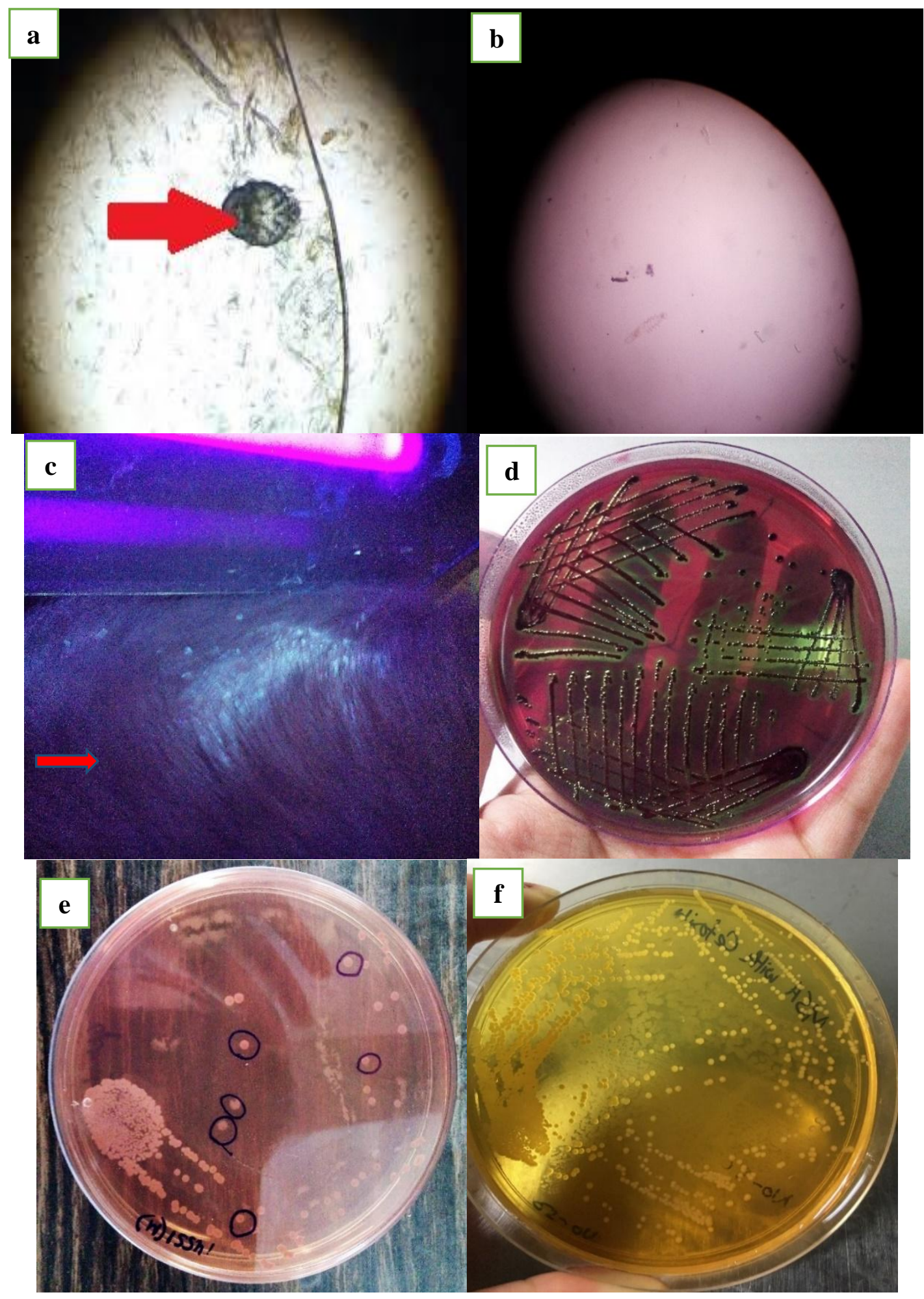


Fig.7 Photograph showing (a) cultures of Tricophyton mentagrophytes in Sabaroud's Dextrose Agar (b) culture of Microsporum canis in Sabaroud's Dextrose Agar. (c) fungal hyphae on lactophenol cotton blue staining. (d) macroconida
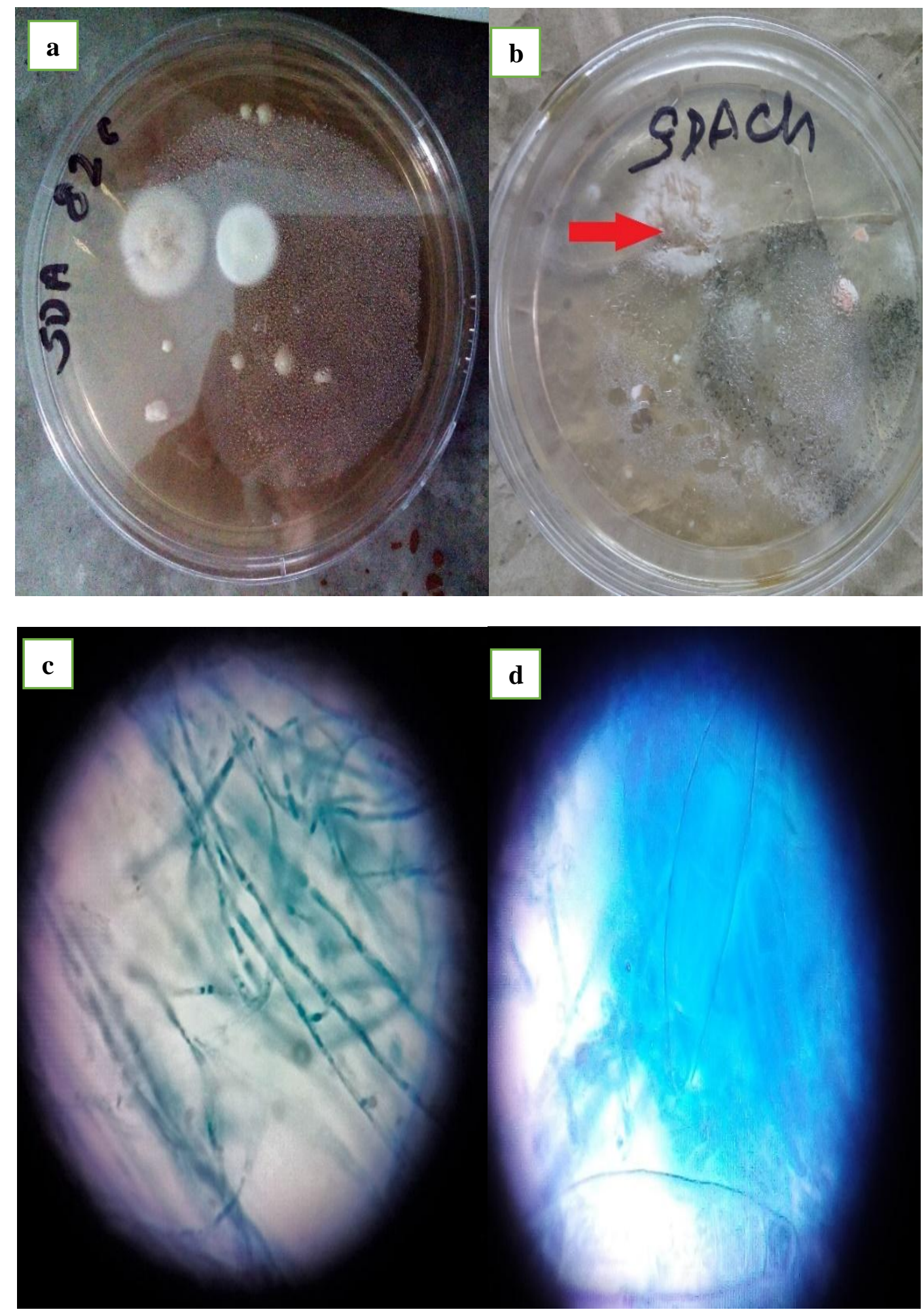
Table.1 Haematological and biochemical values of healthy and infected group of animals

\begin{tabular}{|c|c|c|}
\hline Group & Healthy (n=6) & Infected $(\mathrm{n}=36)$ \\
\hline $\mathrm{Hb}(\mathrm{gm} / \mathrm{dl})$ & $12.93+0.08$ & $10.04 \pm 0.09 * *$ \\
\hline PCV (\%) & $35.67+0.49$ & $33.75+0.18 *$ \\
\hline $\operatorname{TEC}\left(10^{6} / \mathrm{mm}^{3}\right)$ & $6.26+0.12$ & $4.79+0.52^{* *}$ \\
\hline $\operatorname{TLC}\left(10^{3} / \mathrm{mm}^{3}\right)$ & $14.44 \pm 0.32$ & $16.63 \pm 0.17^{* *}$ \\
\hline Neutrophil (\%) & $62.5 \pm 0.43$ & $70.78 \pm 0.19^{* * *}$ \\
\hline Eosinophil (\%) & $5.83 \pm 0.31$ & $7.17 \pm 0.15^{* *}$ \\
\hline Lymphocyte (\%) & $27.83 \pm 0.48$ & $20.42 \pm 0.18^{* *}$ \\
\hline Monocyte (\%) & $3.5 \pm 0.34$ & $1.36 \pm 0.28^{* * *}$ \\
\hline Basophil (\%) & $0.3 \overline{3}+0.21$ & $0.25 \pm 0.07^{\mathrm{NS}}$ \\
\hline Total protein $(\mathrm{gm} / \mathrm{dl})$ & $6.80 \pm 0.14$ & $6.54 \pm 0.031^{\mathrm{NS}}$ \\
\hline Albumin (gm/dl) & $4.67 \pm 0.14$ & $4.36 \pm 0.019^{\mathrm{NS}}$ \\
\hline Globulin (gm/dl) & $2.13 \pm 0.07$ & $2.18 \pm 0.011^{\mathrm{NS}}$ \\
\hline
\end{tabular}

Breed wise occurrences of skin disorders in dogs revealed that Spitz (27.56\%) were more predominantly affected with various kinds of skin disorders than other breeds followed by Labrador (19.87\%), Pomeranian (14.14\%), Non-descript (13.46\%) and Pug (12.82\%) (Fig. 4). The other breeds like Doberman Pinscher, Dalmatian, Boxer, Golden Retriever etc. collectively represented $(12.18 \%)$ since the individual breeds did not significantly contribute to the overall percentage of skin disorders in dogs.

In the present study Spitz were predominantly found to be affected with skin disorders, this has earlier been reported by Kumar et al., 2006 and Sarma et al., 2013. The reason for spitzbeing more predisposed in the present study might be due to their long hair perpetuating the mistness favourable for the harbouring infection in hot and humid climate in majority of months in a year. However, Singh et al., 2012 reported that prevalence of dermatitis was maximum in Mongrel $(67.52 \%)$ followed by German Shepherd (9.02\%), Labrador (6.51\%), Spitz (4.27\%) and Doberman $(3 \%)$. The difference in the findings might be due to the popularity of a certain breed in an area as stated by Pocta and Svoboda (2007) that the breed composition of canine population in a particular region and popularity of the particular breed can affect the results of the breed predilection to dermatological disorders in the examined area.

\section{Haematological and Biochemical alterations}

Haemato-biochemical values in healthy and infected dogs were presented in table 1 . The level of haemoglobin $(\mathrm{gm} / \mathrm{dl})$ in healthy control and affected animals were $12.93+0.08$ and $10.04+0.09$ respectively which clearly shows that the level of haemoglobin was significantly lower $(\mathrm{P}<0.01)$ in dogs that were affected with various nature of skin disorders.

These results are in accordance with the findings of Lodh and Das (2014). Similarly, the values of PCV (\%) and TEC (106/ mm3) in healthy animals were $35.67+.49$ and $6.26+.12$ respectively. The corresponding values in affected dogs were $33.75+.18$ and 
4.79+.52 respectively which shows a significant decrease $(\mathrm{P}<0.01)$ in both the values in the affected group of animals as compared to the healthy animals. These findings corroborated with the findings with Lodh and Das (2014) and Prathibha (2000). Significant lower values of haemoglobin, PCV and TEC indicating anaemia in infected dogs might be due to loss of skin protein due to excessive scratching and stress arising from the diseases (Deb et al., 2000). This is particularly seen in dogs suffering from pyoderma, scabies and demodex. While the reason of anaemia in dogs infected with dermatophytes might be due to less food intake caused by clinical illness and discomfort (Devi and Vijayakumar. 2013). The mean total leucocyte count $(\times 103 / \mathrm{mm} 3)$ in healthy and affected dogs was $14.44+0.32$ and $16.63+0.17$ respectively. The total leucocyte count in the affected group of dogs in this study was elevated significantly $(\mathrm{P}<0.01)$ as compared to the healthy dogs. The mean values (\%) of neutrophil, eosinophil, lymphocyte, monocytes and basophils in healthy dogs were $62.5+0.43$, $5.83+0.31, \quad 27.83+0.48, \quad 3.5+0.34$ and $0.33+.21$ respectively and in affected dogs the corresponding values were $70.78+0.19$, $7.17+0.15, \quad 20.42+0.18, \quad 1.36+0.28$ and $0.25+.07$ respectively. The level of neutrophil, eosinophil was significantly higher $(\mathrm{P}<0.01)$ while the level of lymphocyte and monocyte was significantly lower $(\mathrm{P}<0.01)$ in the affected animals as compared to the healthy animals. This result agreed with the findings of Arlian et al., 1995. Cellular and humoral responses to inflammation on account of hostparasite interaction are the reported reason (Huntley et al., 1995). Skin affected dogs had significantly higher $(\mathrm{P}<0.01)$ neutrophil count $(70.78+0.19)$. Elevated level of neutrophils was earlier reported by Gera et al., 2012 and statistically higher levels of neutrophils in certain bacterial dermatitis were recorded by Pal et al., 1991. The reason for neutrophilia might be due to the injury to the cells which causes the release of substances like leukotoxins and leucocytosis promoting factors from the blood to the site of injury resulting in the release of more neutrophils in the blood stream as stated by Lodh and Das (2014). The level of eosinophils in skin affected dogs were recorded significantly higher $(\mathrm{P}<0.01)(7.17+0.15)$ in comparison to the healthy animals. Significantly higher levels of eosinophils in caninedemodicosis, was reported by Chakraborty and Pradhan (2015). Increase in the level of eosinophil might be due to irritation of the skin tissues which stimulated the mast cells to release more histamine and since histamine is chemotactic for eosinophils, eosinophilia develops (Aujla et al., 2000). The lymphocyte count and monocyte in the present study significantly decreased $(20.42+0.18$ and $1.36+0.28)$ which was in agreement of the findings of Lodh and Das (2014). Stressful condition to the animals affected with skin disorders might be the most probable reason behind it.

The mean serum total protein $(\mathrm{gm} / \mathrm{dl})$, albumin $(\mathrm{gm} / \mathrm{dl})$ and globulin $(\mathrm{gm} / \mathrm{dl})$ in healthy animals were recorded as $6.80+0.14$, $4.67+0.14$ and $2.13+0.07$ respectively. While the in the infected group the values of serum total protein, albumin and globulin were recorded as $7.60 \pm 0.04, \quad 3.61 \pm 0.05$ and $3.99 \pm 0.06$ respectively which indicated that there were significant $(\mathrm{P}<0.01)$ increase in the level of serum total protein, significant decrease in the serum albumin while a decrease in the serum globulin.

These findings are similar to the findings of Mason (1991), Shyma and Vijayakumar (2011) and Lodh and Das (2014). Hyperglobinamia and hypoalbuminemia in bacterial skin diseases were earlier reported by Shyma and Vijayakumar (2011). Increased serum protein in the present study might be 
due to the increased inflammatory responses produced by various pathogens involved in skin disorders. The antigens were trapped in the Langerhan's cells, which were the prominent antigen presenting cells of the skin immune system and presented the antigens to T- lymphocytes (Devi and Vijayakumar (2013). The migration of antigen presenting cells was initiated by cytokines and this leads to dense infiltration of inflammatory cells in the infected area and subsequent increase in serum total protein (Gudding and Lund. 1995).

\section{Acknowledgment}

The authors are thankful to the Head of the Department, Veterinary Medicine, Ethics and Jurisprudence, WBUAFS, Dean and the ViceChancellor, WBUAFS, Kolkata, India for providing all the necessary facilities.

\section{References}

Arlian, L.G., Morgan, M.S., Rapp, C.P. and Vyszenski, M.D.L. (1995). Some effects of sarcoptic mange in dogs. Indian Journal of Parasitology, 81 (5): 695-702.

Aujla, R.S., Singla, L.D., Juyal, P.D. and Gupta, P.P. (2000). Prevalence and pathology of mange-mite infestations in dogs. Journal of Veterinary Parasitology, 14 (1): 45-49.

Ayodhya, S. and Suryanarayana, C. (2006). Epidemiological studies on parasitic dermatitis in canines. Indian Journal of Veterinary Medicine (India).

Chakraborty, S. and Pradhan, N.R. (2015). Canine demodicosis and its herbal and non-herbal treatments. Indian Journal of Canine Practice, 7 (2): 115.

Deb, A.R., Jha, M.K. and Prasad, K.D. (2000). Clinical and haematological changes in dogs infected with Demodexcanis. Journal of Research
Birsa Agricultural University, 12 (2): 281-283.

Devi, T. and Vijayakumar, K. (2013). Prevalence of canine dermatomycosis: Haemato-Biochemical changes in infected dogs. Shanlax International Journal of Veterinary Science, 1 (2): 4145.

Gera, S., Khurana, R., Jakhar, K.K., Garg, S.L. and Arya, S. (2012). Bloodbichemical studies in skin affections in dogs. Indian Journal of Canine Practice, 4 (2): 162-164.

Gudding, R. and Lund, A. (1995). Immunoprophylaxis of bovine dermatophytosis. The Canadian Veterinary Journal, 36 (5): 302.

Hay, R. J. 1992. In: The skin micro flora and microbial skin diseases. W.C. Noble, Cambridge University Press, Cambridge. Pp. 232263.

Hill, P.B., Lo, A., Eden, C.A.N., Huntley, S., Morey, V., Ramsey, S., Richardson, C., Smith, D.J., Sutton, C., Taylor, M.D. Thorpe, E., Tidmarsh, R. and Williams, V. (2006). Survey of the prevalence, diagnosis and treatment of dermatological conditions in small animals in general practice. The Veterinary Record, 158: 533-39.

Huntley, J.F., Patterson, M., McKellar, A., Jackson, F., Stevenson L.M., and Coop, R.L. (1995). A comparison of the mast cell and eosinophil responses of sheep \& goat to gastrointestinal nematode infections. Research in Veterinary Science, 58: 5-10.

Khurana, R., Kumar, T., Agnihotri, D. and Sindhu, N. (2016). Dermatological disorders in canines - a detailed epidemiological study. Haryana Veterinarian, 55: 97-99.

Kumar K, Rao D S T and Ramesh P (2006). Clinical and therapeutic studies on canine Malasseziosis. Indian Journal of Veterinary Medicine, 26: 73-74. 
Lodh, C. and Das, S. (2014). Diagnostic significance of haematobiochemical changes in canine dermatitis. Indian Journal of Canine Practice Volume, 6 (2): 99-102.

Pal, A., Basak, D.N. and Chakrabarti, A. (1991). A note on haematological changes in canine pyoderma. Cheiron, 20: 6.

Počta, S. and Svoboda, M. (2007). Incidence of canine hypersensitivity in the region of north eastern Bohemia. ActaVeterinaria Brno, 76 (3): 451-459.

Prathibha, S., Kumar, A., Sharma, S.D. and Sexena, S.C. (2000). Dermatological disorders in canines. Indian Journal of Veterinary Research, 9: 59-60.

Sarma, K., Mondal, D.B., Sarvanan, M., Kumar, M. and Vijaykumar, H. (2013). Incidence of dermatological disorders and its therapeutic management in canines. IntasPolivet, 14: 186-192.

Schalm, O.W., Jain, N.C. and Carrol, E.J. (1986). In: Veterinary Haematology, $4^{\text {th }}$ edn., Lea and Febiger, Philadelphia. Page, 299.

Scott, D.W., Miller, W.H. and Griffin, C.E. (1995). In: Muller and Krik's small animal dermatology $6^{\text {th }}$ edn., Philadelphia, WB Saunders Company. pp. 882-883.

Scott, D.W., Miller, W.H. and Griffin, C.E. (2001). In: Muller and Krik's small animal dermatology $6^{\text {th }}$ edn., Philadelphia, WB Saunders Company. Page, 230-232, 274-235, 647-650.

Sharma, S. K., Soodan, J. S., Bal, M. S., Khajuria, J. K. and Upadhyay, S. R. (2009). Parasitic dermatitis in canines of
Jammu region. Journal of Veterinary Parasitology, 23 (1): 65-67.

Sharma, S. K., Soodan, J. S., Dutta, T. K., Raina, B. B., and Tikoo, A. (2008). Occurrence of bacterial dermatitis in canines and their antibiogram. Indian Journal of Veterinary Medicine, 28 (2): 126-127.

Sharma, S.K., Soodan, J.S., Hussain, K. and Tikoo, A. (2013). Clinical management of canine bacterial dermatitis. IntasPolivet, 14 (II): 381-384.

Shyma, V.H. and Vijayakumar, K. (2011). Haematobiochemical studies in dogs affected with bacterial dermatitis. Journal of Veterinary and Animal Sciences, 42: 20-22.

Shyma, V.H. and Vijayakumar, K. (2012). Epidemiological studies on bacterial skin infections in dogs. Journal of Veterinary and Animal Science, 43: 4951.

Singh, R., Beigh, S. A., Soodan, J. S., Tikoo, A., and Tantaray, H. (2012).Clinicoepidemiological studies in canine dermatitis. Indian Journal of Canine Practice, 4 (2): 96.

Snedecor, G.W., Cochran, W.G. (1994). Statistical methods, $8^{\text {th }}$ Edition, Iowa State University, USA.

Sumathi, D. and Vasu, K. (2008). Etiology of mycotic dermatitis in dogs. Indian veterinary journal, 85 (8): 887-888.

Summers, J. F., Hendricks, A., and Brodbelt, D. C. (2014). Prescribing practices of primary-care veterinary practitioners in dogs diagnosed with bacterial pyoderma. Biomed Central Veterinary Research, 10 (1): 240.

\section{How to cite this article:}

Geetanjali Thapa and Samar Sarkar. 2018. Occurrence of Canine Skin Disorder and Its Haematobiochemical Alterations. Int.J.Curr.Microbiol.App.Sci. 7(12): 184-195. doi: https://doi.org/10.20546/ijcmas.2018.712.024 